\title{
PRESENTACIÓN
}

\section{ANTONIO CANDIDO Y LAS TRAMAS LITERARIAS DE AMÉRICA LATINA}

En el discurso de agradecimiento al encuentro académico realizado en 1998 en la Universidad de São Paulo con motivo de su cumpleaños número ochenta, Antonio Candido señaló: “...quando penso no tempo decorrido desde que entramos nesta universidade, há mais de 60 anos, verifico que contribuimos bastante para a cultura do país, mas talvez não tenhamos contribuido com a mesma eficiência para alterar o traço básico da sociedade brasileira, que é o progresso desigual" $(1999,98)$. Esta reflexión, suerte de balance sobre el impacto de su trayectoria en los ámbitos cultural y social de su país, encierra claves que ayudan a desdoblar las múltiples capas que caracterizan tanto la obra intelectual como la militancia política de este crítico que acompañó de cerca momentos históricos cruciales para Brasil y América Latina durante el siglo XX y principios del XXI. La mezcla de satisfacción y frustración de sus palabras al terminar un siglo que, desde la América lusoparlante, él protagonizó, sugiere en parte una concepción de la literatura como instrumento para conocer la sociedad con la finalidad siempre ética de dilucidar maneras para que sus habitantes dignifiquen su situación dentro de ella. La idea de que el pensamiento puede estimular acciones a fin de que un grupo humano se alce sobre sus limitaciones y supere las desigualdades que impiden el bienestar de la mayoría nos habla de Antonio Candido como exponente reciente de la tradición humanista de nuestra América, lugar desde donde se puede vincular su obra con la de nombres como Andrés Bello, al concebir pensamiento, literatura y universidad como motores para la modernización de sociedades que, nacidas del colonialismo, han buscado su lugar en el mundo occidental. Reflexionamos sobre la obra de Antonio Candido a un año de su partida porque su trayectoria, al igual que la de otros exponentes del humanismo continental, ofrece herramientas para estudiar comparativamente las genealogías trazadas por la cultura en nuestros diversos espacios americanos.

Una de las primeras cosas que llama la atención al acompañar los recorridos de Antonio Candido con la perspectiva ventajosa de la actualidad es la manera en que docencia, crítica y militancia se manifiestan como proyecto político congruente que armoniza, desde el impulso ético, las diversas facetas de 
su labor pública. Aunque aclara: "Não tenho vocação política. Para mim, a participação foi sempre um dever moral" (en Konder 323), muchos de sus pares, como Roberto Schwarz en el presente número o Francisco Iglésias en ocasión anterior, reconocen el carácter político de su ejercicio docente porque "todo magistério e uma ação política, ainda que o professor não o pretenda" (Iglésias 115). La idea del profesorado como política y de la política como ética, explican los gestos firmes de diferente envergadura contra la exclusión y la opresión, como su oposición al fascismo durante el Estado Novo (19371945), su defensa de la libertad de pensamiento en la Universidad de São Paulo durante la dictadura militar (1964-1985), su consternación por la expansión de dictaduras militares en el Cono Sur -en 1974 le escribe a Rama: "Después que nos separamos, el mundo empeoró mucho, y la situación brasileña también" (en Rocca 73)-, o su nota en apoyo a los estudiantes chilenos movilizados en 2011 por una educación gratuita y de calidad, entre otros. Bajo el mismo signo ético que lo impulsó a apoyar el acceso democrático a la educación sin distinción de clases sociales, según destaca Jorge Fornet en este volumen, Candido contribuyó a materializar la entrada de los trabajadores a la política contingente brasileña. Su militancia en el Partido de los Trabajadores (PT) desde su fundación en 1980, creado para que los sectores más alejados del ejercicio del gobierno pudieran tomar decisiones sobre el destino del país, es explicada en una entrevista del mismo año al diario Folha de São Paulo: "Acho que o PT corresponde a uma tentativa de socialismo democrático, desta vez partindo dos próprios operários, o que é uma coisa totalmente nova no Brasil. Acho que no PT existe a possibilidade de um socialismo democrático combativo, não de um mero reformismo, por causa da sua base operária e da sua alta consciência sindical" (en Konder 323).

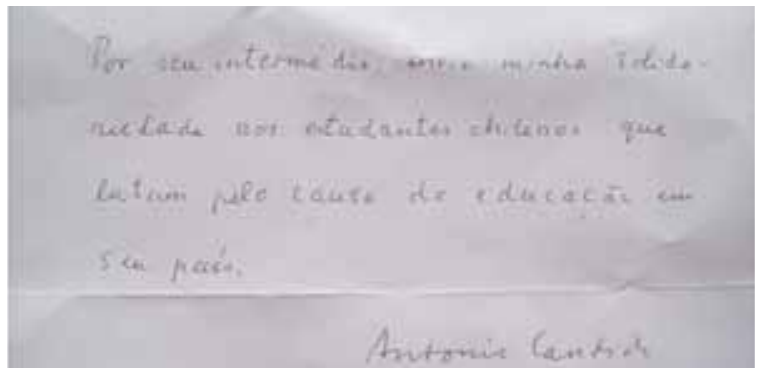

Nota en apoyo a los movimientos estudiantiles chilenos enviada por Antonio Candido en 2011 a través de una de las colaboradoras de este volumen, Rebeca Errázuriz, cuando ella comenzaba a escribir su tesis doctoral sobre este crítico literario. 
El impulso ético es también motor de su trabajo intelectual, al punto de que sus primeras evaluaciones críticas valoran especialmente la contribución de una obra literaria a la sociedad-etapa "funcional" sobre la cual nos habla el trabajo de Rebeca Errázuriz. La extensa carrera de Antonio Candido supone varias transformaciones en su método crítico, no obstante apuntaremos solo algunas notas sumarias acerca de sus propuestas desde la publicación de Formação da literatura brasileira (1959). Este estudio parte de la premisa metodológica de la literatura como un "sistema" que, sin ser historicista a la Ślvio Romero pero tampoco ahistórico, enlaza autor, lectores y contexto a partir de una obra o de un conjunto de ellas. La literatura es concebida, según dice su autor, como "resultado" de la experiencia humana en un espacio específico (su enfoque es nacional) y en una época determinada (escritores diversos que representan problemáticas de su tiempo). Según afirma Octavio Ianni, para Candido la literatura es por tanto "emblema" de la nación (73) y "forma sofisticada de conhecimiento" puesto que "[p]ode revelar o real e o virtual... prefigurando ações e sentimentos, subjetividades e entendimentos, probabilidades do ser e do devir" (81). Es por ello que la crítica tiene el deber -perseguido durante toda la trayectoria de Candido y con una valoración progresiva de la dimensión estética- hallar las claves contenidas en la literatura e interpretarlas con la finalidad de entender la sociedad en que se vive y dilucidar "alguma consequência para a orientação do homem" (en Iglésias 117).

En esta etapa de su carrera, el concepto de "formación" es fundamental según notan autores como Paulo Eduardo Arantes (229), al situar la citada obra en la línea de estudios interpretativos de la realidad nacional como Formação do Brasil contemporáneo (1942) de Caio Prado Júnior o Formação econômica do Brasil (1959) de Celso Furtado, y también de trabajos ensayísticos como Casa-grande e senzala (1933) de Gilberto Freyre o Raizes do Brasil (1936) de Sérgio Buarque de Holanda. A su enfoque inicial basado en la producción literaria de las élites nacionales y en categorías hegemónicas de análisis, se añadirán posteriormente dimensiones como la popular en, por ejemplo, "Dialética da malandragem" (1970) -cuya originalidad radica, para Schwarz, en que ya "não se trata de generalizar a ideologia de classe dominante, como é hábito, mas a de uma classe oprimida" (147)-; y la continental en, por ejemplo, "Literatura y subdesarrollo" (1972) -texto realizado, según Grínor Rojo, "[a] instancias de esta agenda más ambiciosa de inquietudes [en torno a la intervención en el mundo contemporáneo desde las culturas brasileña y latinoamericana] y que por supuesto está ligada a las circunstancias históricas 
que entonces se viven en la región y en el planeta todo" (168). Sin embargo, estos desarrollos de su crítica parecen no mermar la importancia de la variable nacional pues, en una entrevista otorgada a Beatriz Sarlo en 1980, Candido sostiene que "una literatura necesita que sus escritores experimenten la presencia de la nacionalidad: en el nivel de la función ideológica, la voluntad de ser nacional, de ser específico, es muy productiva" (en Rocca 44).

Analizando su obra en un contexto continental y añadiendo otra dimensión al escenario intelectual descrito por Arantes, Agustín Martínez señala que Antonio Candido forma parte de un momento específico de "modernização intelectual" de América Latina de mediados del siglo XX, en que los ensayistas característicos de la etapa anterior fueron sustituidos "pela figura do professor pesquisador, inscrito em uma determinada comunidade científica, que se afastou crescentemente do público culto a que se dirigia o ensaísmo" (300). Una de las consecuencias de este nuevo lugar de enunciación para el ejercicio crítico consistió, según Martínez, "no estudo do comportamento da literatura em suas relações com as tendências dominantes da sociedade e da cultura latino-americana". Tanto estas afirmaciones, como las comentadas en el párrafo anterior, nos llevan a pensar en Antonio Candido como una figura latinoamericana bisagra que engarza tradiciones intelectuales que inician con Andrés Bello y su idea de la literatura como expresión necesaria de una nación moderna que busca participar en la cultura occidental con las herramientas de esta; y que llegan hasta Ángel Rama y el rol activo de la crítica en el "diseñ[o] de "modelos culturales" (en Zanetti 923) que formulen la particularidad local a contrapelo de las imposiciones culturales y económicas del exterior. El parentesco con un letrado como Bello emerge de la similitud de momentos históricos en los que reflexionan sobre la génesis de la cultura local a partir de patrones europeos: Antonio Candido sentía, a pocas décadas de instaurada la república en Brasil y como muchos de sus contemporáneos, que debía contribuir a dar los puntapiés iniciales de la reflexión intelectual sobre las características y desafíos de la literatura brasileña. Es por ello que Formação... se centra en los "momentos decisivos" en que la literatura cultivada por las élites mostró signos de identidad propia, recorrido que paradójicamente culmina en el novelista afrodescendiente Machado de Assis (1839-1908) por haber aprovechado las lecciones de la irregular tradición nacional y de los modelos europeos para crear una obra literaria sin exotismos para ojos imperiales. En esta etapa de la crítica de Candido, conocer la cultura desde la literatura persigue, en última instancia y en diálogo con el espíritu de Raízes do Brasil, aproximarse al alma nacional para estimar su 
"peso" según los referentes de la cultura occidental. Cuando su pensamiento comienza a sintonizar con el pulso crítico de la izquierda continental, se aleja de los modelos culturales de las clases dominantes abriéndole paso, en el decir de Schwarz, a "um modo de ser popular" (148) centrado en la figura del malandro y propuesto como ideología nacional.

El trabajo crítico de Antonio Candido en relación con América Latina -analizado por el estudio de Mary Luz Estupiñán publicado en este volumen- se aprecia especialmente en los diálogos con intelectuales e instituciones del mundo hispanoparlante y en el impulso dado al estudio sistemático de la literatura "hispanoamericana" en universidades de su país. El pensar críticamente sobre la literatura brasileña en el contexto cultural latinoamericano es un desafío derivado de su amistad con el uruguayo Ángel Rama -aspecto abordado más adelante por el estudio de Hugo Herrera- y de su participación en la institución cubana Casa de las Américas - sobre lo cual trata el texto de Fornet. Según constatan los propios autores en su intercambio epistolar, la influencia fue mutua: si por un lado Rama se inspiró en el método crítico de Candido para desplazar sus propias reflexiones literarias desde un enfoque nacional hacia uno continental, Candido reconoce el papel de Rama en la intensificación de la cooperación cultural entre las Américas luso e hispanoparlantes. Sabemos que el concepto de "sistema" articulado por Candido es punto de partida del comparatismo cultural de Rama, el cual esboza en "Un proceso autonómico: de las literaturas nacionales a la literatura latinoamericana" (1979) con la finalidad de superar el estudio literario de una región por la "mera adición de literaturas nacionales" (35). Por su parte, al recibir el Doctorado Honoris Causa de la Universidad de la República en 2006, Candido se refirió al integracionismo militante del uruguayo: "Rama me habló de la necesidad de desarrollar al máximo los intercambios con los escritores y artistas de nuestra América, que en aquel tiempo estaban poco inclinados a una comunicación directa y dependían mucho de la mediación de los países centrales". Candido había conocido personalmente a Rama en 1960 cuando, al calor de la Revolución cubana, este había optado por, como dice el brasileño, "la militancia infatigable a favor del intercambio y de la integración mental de nuestros diversos países" (en Rocca 170). Resulta interesante constatar el acercamiento del brasileño a la tradición cultural latinoamericana en "Literatura y subdesarrollo" donde, junto con ofrecer conceptos para comprender la literatura continental de la primera mitad del siglo XX -algunos esclarecedores y vigentes como el de "país novo" y otros problemáticos y superados como el de "subdesarrollo"- evoca el "somos un 
pequeño género humano" (70) de Bolívar cuando afirma: "Sabemos, pois, que somos parte de uma cultura mais ampla, da qual participamos como variedade cultural" $(1989,154)$.

Antonio Candido tuvo, asimismo, un papel pionero en la inserción sistemática de los estudios de literatura hispanoamericana en la academia brasileña a partir de su primera propuesta en este sentido a la Universidad de Campinas, en 1979. En parte inspirado por el ambicioso proyecto de difusión desde la colección de literatura latinoamericana "Biblioteca Ayacucho" concebida por el uruguayo, Candido era consciente, no obstante, de que se trataría de un esfuerzo más modesto que el de Rama: "Apreciamos mucho tu proyecto para Caracas", le dice, "pero aquí se trata, por el momento, de algo incipiente y tentativo para crecer según las posibilidades" (en Rocca 128). La docencia de literatura hispanoamericana por parte de Candido se hizo extensiva a otras instituciones, como a la Universidad Federal de São Carlos en 1982, así como también la de la literatura brasileña en el mundo académico hispanohablante. En 1976, Rama le pidió a Candido su cuota por la causa latinoamericana cuando lo invitó a discutir sobre los títulos brasileños de la Biblioteca Ayacucho y a dar clases en la Universidad Central de Venezuela: “...De paso podrías dar unas conferencias en nuestra Universidad, donde no se sabe nada nada nada de literatura brasileña y harías un gran bien a la integración del continente en que estoy empeñado" (en Rocca 96).

También las visitas a Casa de las Américas en La Habana contribuyeron a la profundización de espíritu continental de Candido, según le comenta a Rama en 1979: "La impresión causada por Cuba fue extraordinaria. [...] Espero, en adelante, ampliar el conocimiento de América Latina y trabajar un poco, en la vejez, para el acercamiento cultural entre nuestros países, a lo que te has dedicado desde muy joven" (en Rocca 119-120). En este contexto, cabe notar que el pensamiento antiimperialista de José Martí, revitalizado en el continente por la Revolución Cubana, había contagiado a Antonio Candido ya antes de su primera visita a Cuba, según revela al felicitar a Rama por su nombramiento para la Cátedra de Literatura Hispanoamericana en la Universidad de la República en 1967: “Ahora estás en el puesto en el que puedes trabajar en la dirección de tu viejo ideal de tramar a los países de América Latina, para su mutuo e indispensable conocimiento. ¿Qué seremos si no estamos unidos frente a nuestro terrible vecino septentrional? La unión se procesa en todos los niveles, y el de la literatura tiene un valor que no se puede menospreciar" (en Rocca 47). 
Para concluir, proponemos el ejercicio de colocar en tiempo presente la reflexión de Candido: ¿es indispensable el mutuo conocimiento de los países del continente?, ¿tiene la literatura un valor en vistas de este objetivo? El ensayo de Pedro Meira Monteiro, incluido a continuación, propone rutas provocativas en este sentido. Sin pretender dar una respuesta sino iniciar una discusión, tal vez debemos considerar que los flujos migratorios han intensificado la coexistencia de nacionalidades en muchos rincones de las multirraciales y multiculturales Américas, resultando en brotes de xenofobia e intolerancia que erosionan las condiciones de vida de los "extranjeros" e intoxican la convivencia de las sociedades. En este contexto, las tramas literarias a las que se refiere Antonio Candido y que, según hemos sugerido en este comentario, él mismo contribuyó a entretejer, pueden estimular la empatía hacia tantos "otros" que el colonialismo inventó y cartografió en ambos lados de las fronteras nacionales de nuestras Américas. El poder de la literatura para generar respeto por las diferencias ha sido subrayado por muchos autores, como Martha Nussbaum en el citado Cultivating Humanity. A Classical Defense of Reform in Liberal Education (1997). Pero quedémonos con algunas de las palabras que al respecto pronunció Candido en "O direito à literatura" (1988), texto donde la literatura -"fator indispensável de humanização" (2004, 175)- incluye también expresiones menos canónicas de la cultura:

Entendo aqui por humanização... o processo que confirma no homem aqueles traços que reputamos essenciais, como o exercício da reflexão, a aquisição do saber, a boa disposição para com o próximo, o afinamento das emoções, a capacidade de penetrar nos problemas da vida, o senso da beleza, a percepção da complexidade do mundo e dos seres, o cultivo do humor. A literatura desenvolve em nós a quota de humanidade na medida em que nos torna mais compreensivos $\mathrm{e}$ abertos para a natureza, a sociedade, o semelhante $(2004,180)$.

Tal vez resta seguir evaluando, como hizo por ejemplo Julio Ramos en Desencuentros de la modernidad en América Latina (1989), el lugar que en nuestro presente ocupa esta tradición "clásica" de humanismo latinoamericanista de la que Antonio Candido participa.

Mónica González García Coordinadora Dossier Antonio Candido Pontificia Universidad Católica de Valparaíso, Valparaíso, Chile monica.gonzalez@pucv.cl 


\section{BIBLIOGRAFÍA}

Arantes, Paulo Eduardo. "Providências de um crítico literário na periferia do capitalismo". Dentro do texto, dentro da vida. Ensaios sobre Antonio Candido. Maria Angela D'Incao, Eloísa Faria Scarabôtolo (orgs.). São Paulo: Companhia das Letras, 1992. 229-261.

Bolívar, Simón. “Carta de Jamaica”. Para nosotros la patria es América. Caracas: Fundación Biblioteca Ayacucho, 1991.

Candido, Antonio. "Discurso de agradecimento". Antonio Candido: pensamento e militancia. Flávio Aguiar (org.). São Paulo: Fundação Perseu Abramo, Humanitas Publicações FFLCH, USP, 1999. 96-99.

"Literatura e subdesenvolvimento". A educação pela noite e outros ensaios. São Paulo: Editora Ática, 1989.

"O direito à literatura”. Vários escritos. São Paulo: Duas Cidades, Rio de Janeiro: Ouro sobre Azul, 2004. 169-191.

Ianni, Octavio. "Nação e narração". Antonio Candido: pensamento e militancia. Flávio Aguiar (org.). São Paulo: Fundação Perseu Abramo, Humanitas Publicações FFLCH, USP, 1999. 71-81.

Iglésias, Francisco. “Antonio Candido, o escritor e o político”. Esboço de figura. Homenagem a Antonio Candido. Celso Lafer (org.). São Paulo: Duas Cidades, 1979. 101-120.

Konder, Leandro. "A sabedoria humilde na firmeza do engajamento". Dentro do texto, dentro da vida. Ensaios sobre Antonio Candido. Maria Angela D’Incao, Eloísa Faria Scarabôtolo (orgs.). São Paulo: Companhia das Letras, 1992. 319-324.

Martínez, Agustín. "Radicalismo e latino-americanismo". Dentro do texto, dentro da vida. Ensaios sobre Antonio Candido. Maria Angela D’Incao, Eloísa Faria Scarabôtolo (orgs.). São Paulo: Companhia das Letras, 1992. 297-318.

Rama, Ángel. "Un proceso autonómico: de las literaturas nacionales a la literatura latinoamericana". Proceedings VII, I (1979): 35-42.

Rocca, Pablo. Ed. Un proyecto latinoamericano. Antonio Candido \& Ángel Rama, correspondencia. Montevideo: Estuario Editora, 2016.

Rojo, Grínor. De las más altas cumbres. Teoría crítica latinoamericana moderna (1876-2006). Santiago de Chile: LOM, 2012.

Schwarz, Roberto. "Pressupostos, salvo engano, de 'Dialética da malandragem'”. Esboço de figura. Homenagem a Antonio Candido. Celso Lafer (org.). São Paulo: Duas Cidades, 1979. 133-154.

Zanetti, Susana. "Ángel Rama y la construcción de una literatura latinoamericana”. Revista Iberoamericana, Vol. XVII, 160-161 (julio-diciembre 1992): 919-932. 